\title{
Nuclear receptor TLX prevents retinal dystrophy and recruits the corepressor atrophin 1
}

\author{
Chun-Li Zhang, ${ }^{1,2}$ Yuhua Zou, ${ }^{2}$ Ruth T. Yu, ${ }^{2}$ Fred H. Gage, ${ }^{3}$ and Ronald M. Evans ${ }^{1,2,4}$ \\ ${ }^{1}$ Howard Hughes Medical Institute, ${ }^{2}$ Gene Expression Laboratory, and ${ }^{3}$ Laboratory of Genetics, The Salk Institute \\ for Biological Studies, La Jolla, California 92037, USA
}

\begin{abstract}
During mammalian embryogenesis, precise coordination of progenitor cell proliferation and differentiation is essential for proper organ size and function. The involvement of TLX (NR2E1), an orphan nuclear receptor, has been implicated in ocular development, as $\mathrm{Tl}^{-/-}$mice exhibit visual impairment. Using genetic and biochemical approaches, we show that TLX modulates retinal progenitor cell proliferation and cell cycle re-entry by directly regulating the expression of Pten and its target cyclin D1. Additionally, TLX finely tunes the progenitor differentiation program by modulating the phospholipase $\mathrm{C}$ and mitogen-activated protein kinase (MAPK) pathways and the expression of an array of cell type-specific transcriptional regulators.

Consequently, $\mathrm{TlX}^{-/-}$mice have a dramatic reduction in retina thickness and enhanced generation of S-cones, and develop severe early onset retinal dystrophy. Furthermore, TLX interacts with atrophin1 (Atn1), a corepressor that is involved in human neurodegenerative dentatorubral-pallidoluysian atrophy (DRPLA) and that is essential for development of multiple tissues. Together, these results reveal a molecular strategy by which an orphan nuclear receptor can precisely orchestrate tissue-specific proliferation and differentiation programs to prevent retinal malformation and degeneration.
\end{abstract}

[Keywords: Nuclear receptor; TLX; retinal dystrophy; PTEN; atrophin; neurodegeneration]

Supplemental material is available at http://www.genesdev.org.

Received January 26, 2006; revised version accepted March 15, 2006.

The mammalian central nervous system (CNS) is comprised of a variety of cell types. Proliferation and differentiation are major forces driving its formation. Commitment of multipotent progenitor cells to specific lineages and precise organization of the generated cell types determine regional identity, while production of sufficient cell numbers governs size. Correct balancing of these two events is required for a functional CNS of the proper size and cytoarchitecture. Nonetheless, how this balance is achieved is poorly understood.

The retina is an ideal model system to study CNS formation, as it is easily accessible, has a relatively simple structure, and is constituted by a manageable number of cell types; namely, six neuronal cell types and one class of glia, which are organized into three characteristic cellular layers. The light-sensing rod and cone photoreceptors are localized in the outer nuclear layer $(\mathrm{ONL})$, while projection neurons occupy the innermost ganglion cell layer (GCL). Separating these two layers is the inner nuclear layer (INL) containing amacrine, bipo-

${ }^{4}$ Corresponding author.

E-MAIL evans@salk.edu; FAX (858) 455-1349.

Article and publication are at http://www.genesdev.org/cgi/doi/10.1101/ gad.1413606. lar and horizontal interneurons, and Müller glia. Birth dating analyses have demonstrated that all seven cell types are generated from a common progenitor cell in an evolutionarily conserved order; ganglion, horizontal, and cone cells are born first, followed by the remaining cell types in overlapping phases (Price et al. 1987; Turner and Cepko 1987). Thus, the timing of proliferation and differentiation of the retinal progenitor cells (RPCs) must be tightly modulated to produce sufficient numbers of all of the necessary cell types. While emerging evidence shows that cell type specification and differentiation from the RPCs is controlled by a series of intrinsic factors, such as homeobox-containing genes (Mathers and Jamrich 2000; Martinez-Morales et al. 2001; Dyer 2003) and bHLH (basic helix-loop-helix) proteins (Hatakeyama and Kageyama 2004), little is known about how the tissue-specific proliferation is modulated and how these two processes are coordinated.

Nuclear receptors constitute a superfamily of transcription factors characterized by a DNA-binding domain (DBD) and a ligand-binding domain (LBD) (Mangelsdorf and Evans 1995). TLX belongs to the so-called orphan nuclear receptor family for which ligands have not yet been identified (Yu et al. 1994). Its expression starts at embryonic day 8 (E8) and is localized in the 
neuroepithelium of the developing CNS, including telencephalon, diencephalon, nasal placodes, neural retina, and optic stalk (Yu et al. 1994). Loss of TLX function in mouse leads to reduced brain size, thin cerebral cortices, and visual impairment (Monaghan et al. 1997; Yu et al. 2000). TLX also plays an essential role in maintaining the proliferative state of adult neural stem cells in mouse forebrain (Shi et al. 2004); but the genetic circuits by which TLX regulates neural progenitor proliferation are unclear. Using combined genomewide expression profiling and histological and biological analysis, we show that TLX interacts with the corepressor atrophin1 (Atn1) and is required for coordinating retina-specific proliferation and differentiation programs to prevent retinal dystrophy, while it is not essential for retinal cell type specification.

\section{Results}

Dystrophic retina and loss of visual acuity in $\mathrm{TlX}^{-/-}$mice

Previously we have shown that $T \mathrm{x}^{-/-}$mice have visual defects (Yu et al. 2000). To further characterize these defects, we performed immunostaining on flat-mounted neural retinas from adult $\mathrm{TlX}^{-/-}$or wild-type mice using an antibody (against rhodopsin) that recognizes the outer segments (OS) of rod photoreceptors. Unlike the continuous and compact staining of the wild-type retinas, there are numerous unstained "voids" in the $\mathrm{TlX}^{-/-}$retinas (indicated by arrows in Fig. 1A,B). Retinal voids are preceded by zones of OS thinning at earlier developmental stages (postnatal day 10 [P10]) (Fig. 1C) that progress to patchy fenestrations beginning around P21 (Fig. 1D).

Although $\mathrm{TlX}^{-/-}$mice lack a normal light response as measured by electroretinograms (Yu et al. 2000), their loss of visual acuity has not been directly examined. On the standard visual cliff paradigm (Crawley 2000), we found that $\mathrm{TlX}^{-/-}$mice cannot distinguish the cliff and spend equal amounts of time on either side of the cliff edge, indicating complete loss of visual acuity (Fig. 1E). This conclusion was further strengthened by results from light/dark transition tests, in which $\mathrm{TlX}^{-/-}$mice fail to recognize the safe environment of the dark box (Fig. $1 \mathrm{~F})$ and spend $80 \%$ of the time in the well-lit box relative to $20 \%$ for the wild-type controls (Fig. 1G).

\section{Reduced retinal size and cell number in $\mathrm{TlX}^{-/-}$mice}

To understand the cellular mechanisms underlying the loss of vision found in $\mathrm{TlX}^{-/-}$mice, we conducted detailed histological analyses of mutant eyes from E10.5 to adulthood. Between E10.5 and E14.5, no obvious histological defects were observed (data not shown). However, beginning at E15.5 and particularly by E16.5, the $\mathrm{Tl}^{-/-}$ neural retinas were significantly thinner $(16 \%$ at E16.5 and $43 \%$ at P21) than that of wild-type littermates (Fig. 2A-D; data not shown). This was most evident in the

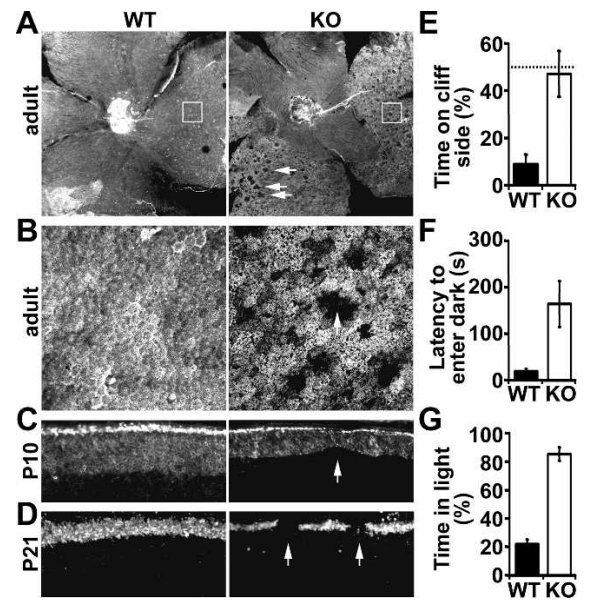

Figure 1. Retinal degeneration and blindness in TLX mutant mice. $(A, B)$ Flatmounts of adult retinas immunostained for rhodopsin showing degenerative regions (indicated by arrows). (A) View of the entire retina. $(B)$ Higher magnification of boxed area in $A .(C, D)$ Cross-sections of the retinas from $\mathrm{P} 10(C)$ and $\mathrm{P} 21$ $(D)$ stained for rhodopsin. Arrows indicate degenerative areas. (E) Behavioral visual acuity by visual cliff tests. $\mathrm{TlX}^{-/-}$mice spent equal amounts of time on both sides of the cliff edge. Dotted line indicates chance performance. $N \geq 8 ; P<0.001$. $(F, G)$ Light/dark transition tests. $T x^{-/-}$mice take much longer to enter dark box $(F)$ and spent most of the time in the light environment $(G) . N \geq 8 ; P<0.001$.

late-forming nuclear layers such as the INL and ONL (Fig. 2A,C,D).

Thinning of the retina could be caused by reduction in cell size and/or number. Confocal microscopy showed that while there was no significant difference in nucleus size (data not shown), there was a marked reduction in the thicknesses of the inner plexiform layer (IPL), outer plexiform layer (OPL), and photoreceptor OS, which indicates shortened axons and dendrites (Fig. 2A). To compare cell numbers, neural retinas were dissociated and stained for nuclei. Total nuclei counts revealed that mutant retinas had nearly $50 \%$ fewer cells at P0 and P10 (Fig. 2E). We conclude that a dramatic reduction of cell number and a proportional reduction in both axonal and dendritic length result in an overall thinner retina in the $\mathrm{TlX}^{-/-}$mice. Additionally, we noticed many scattered clusters of cells in the mutant retinas that aberrantly protrude from the INL into the IPL and ONL, and from the ONL into the OS (Fig. 2A), defects resembling those found in cyclin $\mathrm{D1}^{-/-}$and Foxn4 ${ }^{-/-}$retinas (Ma et al. 1998; Li et al. 2004) and suggesting improper cell migration and/or differentiation.

The major classes of cell types in the mouse retina can be identified by morphology, location, and antigenic markers. Immunohistochemistry was performed on cryosections from E16.5, P0, P4, P10, P21, and P28 with various markers specific for each retinal cell type. Strikingly, despite the severity of the retinal thinning, all seven cell types could be identified, indicating that they are normally generated, and demonstrating that TLX is not required for cell type specification (Fig. 3). 


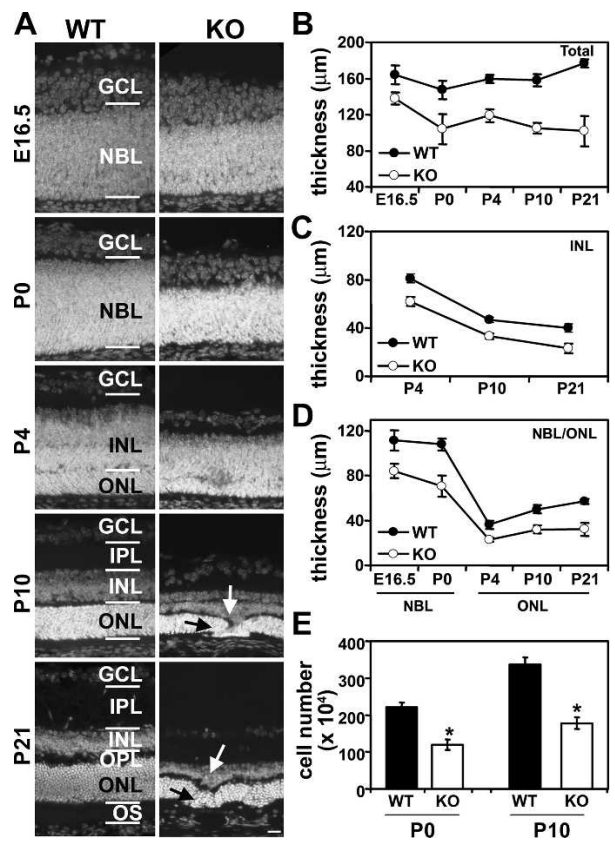

Figure 2. Hypoplasic and dysplasic retina in $\mathrm{Tlx}^{-1-}$ mice. $(A)$ Nuclear staining of the retinal cell layers. Clusters of cells protruding from the INL into the IPL and ONL or from the ONL into the OS of the photoreceptors are indicated by arrows. (GCL) Ganglion cell layer; (INL) inner nuclear layer; (IPL) inner plexiform layer; (NBL) neural blast layer; (ONL) outer nuclear layer; (OPL) outer plexiform layer; (OS) outer segment. Bar, $20 \mu \mathrm{m}$. $(B-D)$ Thicknesses of all nuclear layers $(B)$, INL $(C)$, or ONL $(D)$ were measured in central retinal sections. $N=5 ; P<0.002$ at each point. $(E)$ Cell numbers were counted for each retina. $\left.N=4 ;\left.\right|^{*}\right) P<0.002$.

\section{Extended cell cycle and increased apoptosis in $\mathrm{TlX}^{-/-}$retina}

The retinal phenotype of the $T \mathrm{x}^{-/-}$mice might result from a reduction in cell proliferation, early cell cycle withdrawal, and/or increased cell death. Cell proliferation was examined by in vivo BrdU incorporation to label cells in S phase. Significantly fewer labeled cells ( $\sim 70 \%$ reduction) were observed in $\mathrm{Tlx}^{-/-}$retinas than in controls, which was confirmed in dissociated cells (Fig. $4 \mathrm{~A}, \mathrm{~B})$. To examine the cell cycle dynamics in further detail, total dissociated retinal cells from P0 mice were quantified for the fraction of proliferating cells, which were identified by Ki67 staining. Ki67 is a nuclear protein that is expressed in all phases of the cell cycle except the resting phase (Scholzen and Gerdes 2000). Thus, the fraction of Ki67 negative cells represents the relative number of cells that have exited from the cell cycle. Examination of cells from seven retinas revealed a $32 \%$ increase in cells that exited from the cell cycle in mutant versus control retinas (Fig. 4C).

In mammalian cells, the length of the G1 phase controls the rate of cell proliferation while the $S$ phase remains rather constant (DiSalvo et al. 1995). Therefore the relative cell cycle length can be estimated by the percentage of proliferating cells labeled by a brief pulse of
BrdU. If the cell cycle is prolonged, the relative proportion of proliferating cells labeled by BrdU incorporation will decrease. Quantification indicated that the rate of RPC proliferation was markedly reduced in $\mathrm{TlX}^{-/-}$retinas (Fig. 4D). In addition, results from FACS analysis also pointed to a significant reduction of cells in S phase, which was accompanied by the complementary increase of cells in G0/G1 phase (Fig. 4E).

Apoptosis occurs during normal retinal development, and its increase may contribute to the reduction of total retinal cell number. We examined this possibility by TUNEL assays in retina sections from various developmental stages (Fig. 4F,G). Quantification of TUNELpositive cells showed a consistent increase in apoptotic cells in $\mathrm{TlX}^{-/-}$retinas starting from P0. By P21, few apoptotic cells were observed in controls, but continuous cell death occurred in $\mathrm{TlX}^{-/-}$retinas, often in clusters (Fig. 4F).

\section{Global gene regulation by TLX}

TLX belongs to the nuclear receptor superfamily of transcription factors. We reasoned that the phenotype ob-
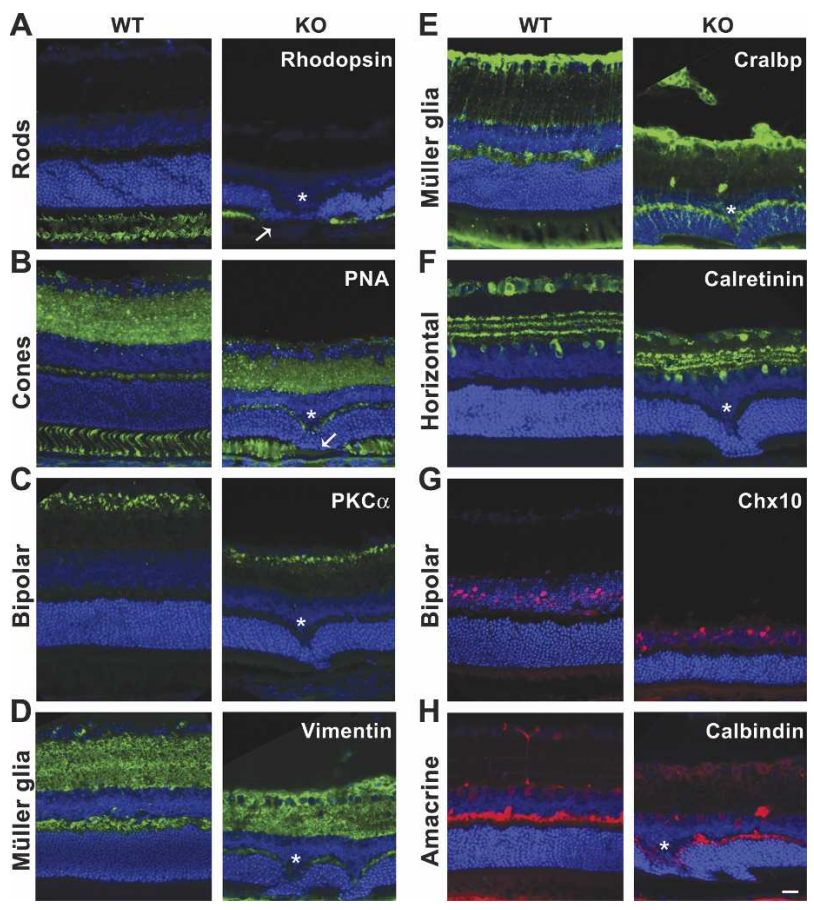

Figure 3. Normal cell-type specification in $\mathrm{Tl}^{-/-}$retina. Cryosections of neural retinas from E16.5 to P21 mice were stained for cell-type-specific markers (red or green) by immunohistochemistry. The sections were then counterstained for nuclei to reveal the nuclear layers (blue). Typical images from P21 sections are shown. $(A, B)$ Immunohistochemistry for rods (rhodop$\sin$ ) and cones (PNA). Asterisks indicate the protrusions from inner nuclear layer. Please note the discontinuous staining for rods and cones (arrows) around the protrusions. $(C, G) \mathrm{PKC} \alpha$ and Chx10-positive bipolar cells. $(D, E)$ Vimentin- and Cralbppositive Müller glia. $(F, H)$ Calretinin- and calbindin-positive horizontal cells. $(H)$ Calbindin-positive amacrine cells. 

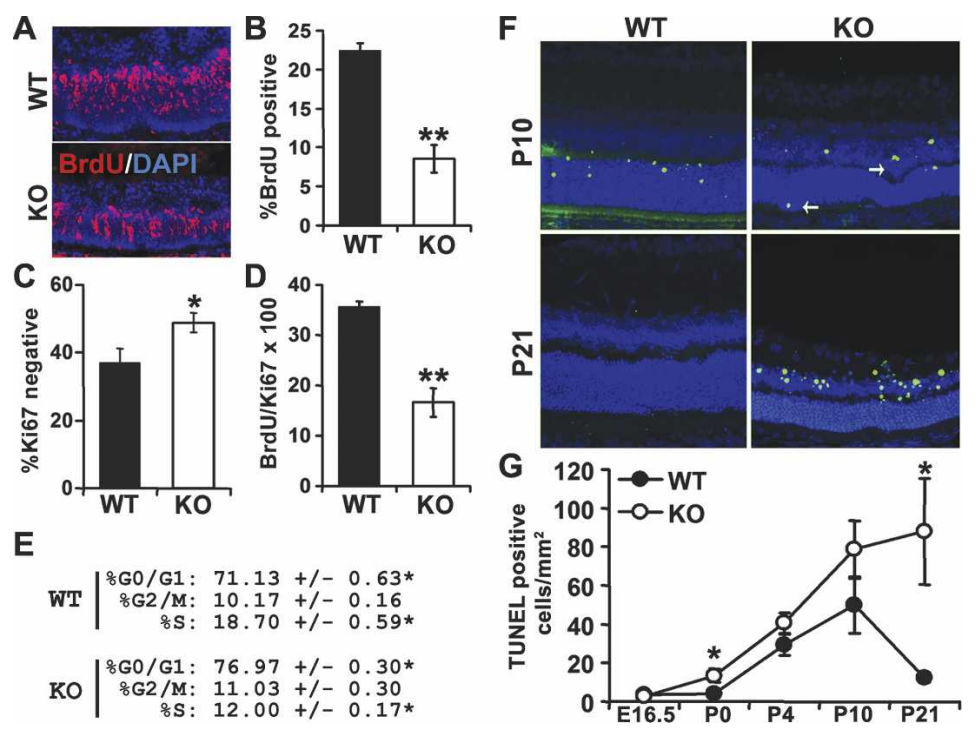

Figure 4. Cell cycle progression defects and increased apoptosis in $\mathrm{TlX}^{-/-}$retinas. (A) Immunohistochemistry of BrdU-positive, dividing retinal progenitors at E16.5 (red signal). $(B-D)$ Progenitor cells from P0 retinas ( $N=4$ per group) were identified by Ki67 staining while cells in mitosis were stained by anti-BrdU antibody. Relative cell cycle length is represented as the ratio BrdU/Ki67. $\left(^{\star}\right) P<0.01$; $\left(^{\star \star}\right) P<0.0001$. (E) DNA contents of cells from $P 0$ retinas $(N=6)$ were analyzed by FACS. $\left({ }^{\star}\right) P<0.001 .(F)$ Neural retinas from E16.5 to P21 eyes were analyzed for apoptosis by TUNEL (green) and counterstained for nuclei (blue). Samples from P10 and P21 are shown. Arrows indicate dysplasic regions in $\mathrm{TlX}^{-/-}$mutant retinas. $(G)$ Quantification of TUNELpositive cells at indicated stages. $\left(^{*}\right) P<0.04$.

served in $\mathrm{TlX}^{-/-}$mice may be caused by dysregulation of a series of genes controlled by TLX. To identify those genes, we performed global expression analyses at E15.5 and P0, two critical points during mouse RPC proliferation and differentiation (Marquardt and Gruss 2002). At E15.5, early-born neurons, which include ganglion, cone, horizontal, and amacrine cells, are at the peak of their differentiation, while the late-born neurons are just emerging. At this stage, RPCs undergo rapid proliferation to expand the progenitor pool in order to give rise to sufficient numbers of early- and late-born neurons. By birth, the specification of early-born neurons is nearly complete, while late-born neurons are undergoing expansion.

Total RNA from neural retinas (nine mice per genotype per developmental stage) were used in gene expression profiling analysis. Known genes that had at least 1.6-fold changes with $p \leq 0.05$ were clustered by biological functions, which were derived from Gene Ontology (Fig. 5A,B; Supplementary Tables S1, S2). A total of 83 and 130 known genes showed changes at E15.5 and P0, respectively. Transcription factors and related proteins
A

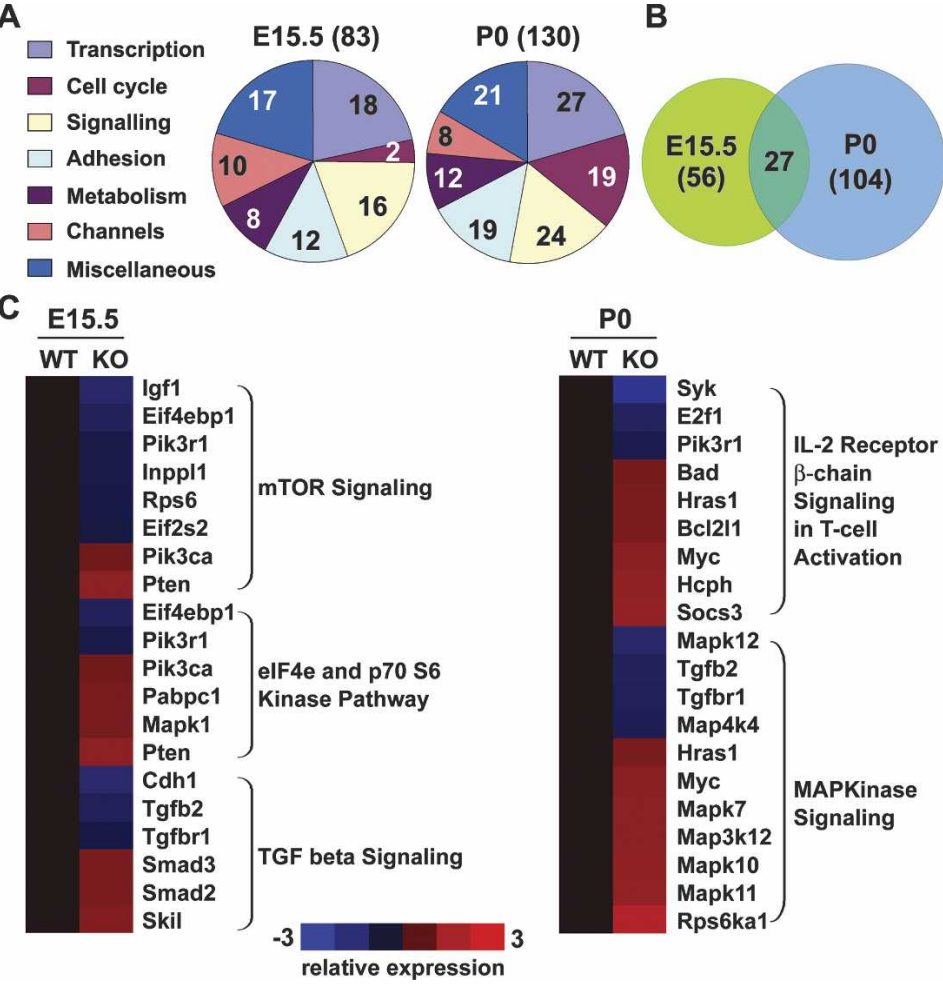

Figure 5. Systematic regulation of genes involved in diverse processes of retinal development by TLX. (A) Clustering and distribution of known genes identified in the expression profiling with a $p$ value $\leq 0.05$ and a minimum 1.6-fold change at E15.5 and P0, respectively. (B) Twenty-seven known genes showed significant changes at both E15.5 and P0. (C) Signaling pathways significantly perturbed in $\mathrm{Tlx}^{-/-}$retinas at either E15.5 or P0. 
comprised the largest group at both stages, with 18 genes at E15.5 and 27 genes at P0. The next largest group included genes involved in signal transduction, such as chemokines and their receptors, G-protein-coupled receptors and calcium channels, with changes in 24 genes at P0 and 16 genes at E15.5. Comparison between the two developmental stages revealed that, while the expression of 27 known genes changed at both stages, 56 genes had significant changes only at E15.5 and 103 genes only at $\mathrm{P} 0$, suggesting stage-specific regulation of target gene expression by TLX (Fig. 5A,B; Supplementary Tables S1, S2).

Microarray data sets were further annotated for BioCarta signaling pathways through the VAMPIRE suite analyses (Hsiao et al. 2005). The expression of several genes was identified as being significantly altered in $\mathrm{TlX}^{-1-}$ retinas (Fig. $5 \mathrm{C}$ ). Of these, TGF $3, \mathrm{mTOR}$, eIF4e, and p70 S6 kinase signaling pathways were largely changed at E15.5, while many components of mitogenactivated protein (MAP) kinase and IL-2 receptor $\beta$-chain signaling were altered at $\mathrm{P} 0$. In response to mitogens, the mTOR-p70 S6 kinase pathway plays a central role in translational regulation, which in turn controls cell growth and cell cycle progression (for review, see Gingras et al. 2001). On the other hand, signaling through IL-2 receptor $\beta$-chain leads to T-cell proliferation and survival. The unexpected alteration of this pathway in $\mathrm{TlX}^{-/-}$retinas implies that a similar mechanism might be employed during retinogenesis. Similarly, the changes in TGF $\beta$ and MAP kinase signaling pathways are consistent with their known roles in regulation of cell growth, proliferation, and differentiation.

\section{Regulation of Pten-Cyclin D1 expression by TLX}

Among the 27 genes that exhibited a change in expression between wild-type and $T \mathrm{XX}^{-/-}$retinas at both $\mathrm{E} 15.5$ and P0, one of the most intriguing was Pten, which negatively regulates neural stem cell proliferation (Supplementary Table S1). We further confirmed its expression by quantitative RT-PCR (Q-PCR) analysis in independent RNA pools from wild-type and mutant retinas at E14.5 and P0. The fold changes were consistent with that from microarray gene profiling, with 1.6- and 2.2-fold up-regulation at E14.5 and P0, respectively (Fig. 6A). The changes in mRNA levels were reflected in the levels of PTEN protein, which were analyzed by Western blotting using specific antibodies (Fig. 6C).

The Akt/PKB signaling pathway, which modulates cell proliferation and survival, is a known PTEN target (Downward 2004). To test whether up-regulation of PTEN leads to altered Akt signaling, we examined the activation status of Akt and its upstream activating kinase, PDK1, by using antibodies that specifically recognize the activated forms. However, no significant changes were observed, suggesting that the Akt pathway itself was not altered in $\mathrm{TlX}^{-/-}$retinas (data not shown).

Other downstream targets of PTEN include p27kip1 and cyclin D1 (Gottschalk et al. 2001; Weng et al. 2001a). Studies have demonstrated that the cyclin kinase inhibi-

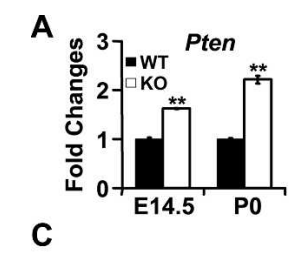

B

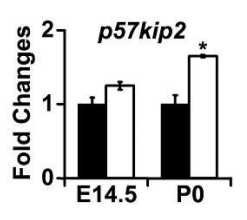

D

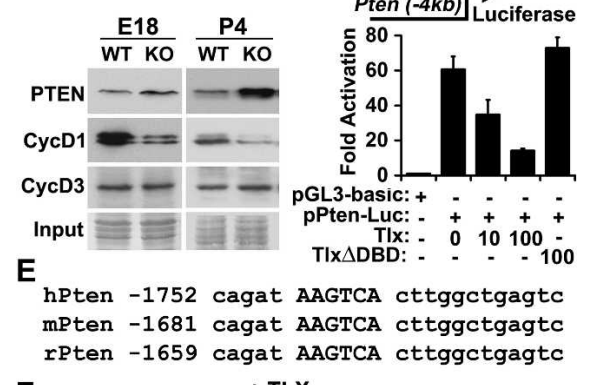

$\mathbf{F}$

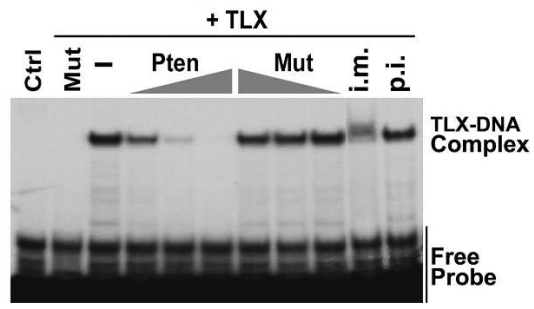

Figure 6. Regulation of Pten-cyclin D1 expression by TLX in retinas. $(A, B)$ Q-PCR analysis of candidate genes in $\mathrm{Tl}^{-/-}(\mathrm{KO})$ and wild-type (WT) retinas at E14.5 and P0 $(N=6$ in triplicate for each group). Gene expression was normalized to that of Hprt and presented as fold changes against wild-type expression. $\left(^{\star}\right)$ $\left.P<0.05 ;\left.\right|^{* \star}\right) P<0.01$. $(C)$ Protein expression of candidate genes in E18 and P4 retinal extracts by Western blotting. Ponceau staining of the membrane serves as input controls (input). (Cyc D1) Cyclin D1; (Cyc D3) cyclin D3. (D) Regulation of Pten promoter activity by TLX. Values are expressed as relative luciferase activity compared with that of the control reporter pGL3basic. (E) Evolutionally conserved sequence in Pten promoter that can be bound by TLX. The numbers indicate distance from the translation start site. $(F)$ Direct binding of TLX to the Pten promoter region in gel shift assays. TNT lysates were used as a control (Ctrl). Binding activity of TLX to DNA was competed away by unlabeled wild-type (Pten) but not mutant (Mut) oligos. The TLX-DNA complex is supershifted with an antibody against the epitope tag on the protein (i.m.) but not by a control antibody (p.i.).

tors p27kip1 and p57kip2 play important roles in regulating RPC proliferation (Dyer and Cepko 2001). By QPCR analysis, the expression of p27kip1 was found to be similar in wild-type and mutant retinas, while p57kip2 expression was increased $>50 \%$ in $\mathrm{TlX}^{-/-}$mutants, consistent with its function as a negative regulator of RPC proliferation (Fig. 6B; Dyer and Cepko 2001; data not shown). Western blot analysis revealed that cyclin D1 protein levels were markedly lower in mutant retinas; this effect was specific since the expression of cyclin D3 was not altered (Fig. 6C). Together, these data suggest that the proliferation defects observed in $\mathrm{TlX}^{-/-}$retinas may result from down-regulation of cyclin D1 via overexpression of PTEN.

TLX is a transcriptional repressor (Yu et al. 2000; Shi 
et al. 2004), raising the possibility that it might directly inhibit Pten expression. We tested this hypothesis with a luciferase reporter construct under the control of the Pten promoter. Expression of full-length TLX in NIH3T3 cells resulted in a striking suppression of Pten reporter activity in a dose-dependent manner; this suppression requires DNA binding of TLX since a truncated version of TLX lacking the DBD (TLX $\Delta \mathrm{DBD}$ ) cannot repress this reporter (Fig. 6D). Analysis of the Pten promoter region identified a stretch of evolutionally conserved sequence containing the consensus TLX-binding site (Fig. 6E). In gel shift assays TLX can directly bind to this sequence (Fig. 6F). This binding was sequence specific since mutations in the core recognition sites (Mut) abolished the formation of DNA-protein complexes. Together, these data suggested that TLX modulates the expression of Pten by directly binding to its promoter.

\section{Enhanced neuronal differentiation in $\mathrm{Tlx}^{-/-}$retina}

Pou4f3 was among the transcription factors that showed significant up-regulation in $\mathrm{TlX}^{-/-}$retinas at both E15.5 and P0 (Supplementary Table S1). It belongs to a subfamily of POU domain-containing factors essential for retinal ganglion cell (RGC) differentiation and survival, including Pou4f1, Pou4f2, and Pou4f3 (Liu et al. 2000, 2001; Wang et al. 2002). Since Pou4f1 and Pou4f2 were not represented in the Affymetrix chips we used, we further examined the expression of all three genes by QPCR analysis using independent pools of retinal RNAs isolated from various developmental stages. Although the expression of Pou $4 f 2$ was not significantly altered (except at P0), Pou4f1 and Pou4f3 expression were dramatically up-regulated in the mutant retinas at both E14.5 and P0 (Fig. 7A). Since ectopic expression of any one of the Pou4f factors has been shown to promote RGC differentiation during retinogenesis (Liu et al. 2000), our data suggested an enhancement of RGC differentiation in $\mathrm{TlX}^{-/-}$retinas during development.

bHLH transcription factors are another family of proteins that play dominant roles in promoting neuronal differentiation (Hatakeyama and Kageyama 2004). Although no changes were identified for neurogenin 1 (Ngn1), neurogenin 2 (Ngn2), and NeuroD in our global expression analysis at E15.5 and P0, we checked the expression of these genes by Q-PCR at more developmental stages and found that Ngn1 was specifically and significantly up-regulated at P5 in the $T \mathrm{x}^{-/-}$retinas (Fig. 7A; data not shown). Global gene analysis also identified another bHLH factor, Bhlhb4, which was ectopically expressed at E14.5, but down-regulated at P14 in mutant retinas. Since Bhlhb4 is required for the maturation and survival of rod bipolar cells (Bramblett et al. 2004), our results imply that TLX plays a role in suppressing key transcriptional programs controlling the differentiation and apoptosis of rod bipolar cells. The predicted increase in the pan-neuronal marker $\beta$ III-tubulin in $\mathrm{TlX}^{-/-}$retinas further supports the proposal that TLX controls cell proliferation by preventing premature cell cycle exit and precocious differentiation (Fig. 7B).
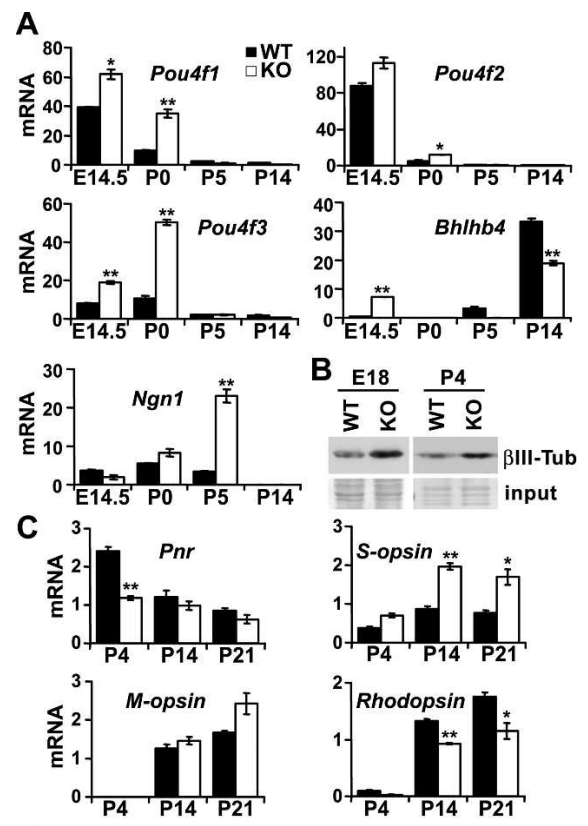

B $\underline{E 18} \quad \mathrm{P4}$

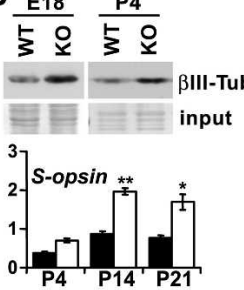

D

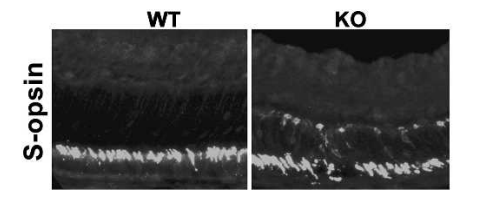

Figure 7. Modulating the expression of cell-type-specific genes by TLX. (A) Quantitative analyses of mRNA by Q-PCR at the indicated developmental stages. Gene expression was normalized to that of Hprt. $N=9 ;\left(^{\star}\right) P<0.04 ;\left(^{\star *}\right) P<0.004$. $(B)$ Western blotting for a pan-neuronal marker $\beta$ III-tubulin. Ponceau staining shows equal loading of the protein. $(C)$ Altered expression of photoreceptor genes assayed by Q-PCR. $\left.N=9 ; \quad{ }^{*}\right)$ $\left.P<0.04 ;^{(\star \star}\right) P<0.004$. (D) Immunostaining using a cone-specific marker (S-opsin) showing enhanced S-cones in $\mathrm{TlX}^{-/-}$retina.

\section{Mutation of TLX results in enhanced S-cone syndrome}

Previous studies have shown that mutation of either $\mathrm{Nrl}$ or the TLX-related receptor Pnr (nr2e3) leads to enhanced S-cone syndrome in humans and mice, characterized by an excess of S-cones and reduced rod photoreceptors (Haider et al. 2000; Mears et al. 2001). S-cones respond to blue (short wavelength) light while $\mathrm{M}$-cones respond to green (middle wavelength) light. Importantly, the expression of $\mathrm{Pnr}$ and $\mathrm{Nr}$ in the $\mathrm{TlX}^{-1-}$ retina was down-regulated at PO by 1.9- and 1.7-fold, respectively (Supplementary Table S2), prompting us to examine whether these retinas had excess S-cones. While the expression of rhodopsin was decreased and that of $\mathrm{M}$-opsin was unchanged in $\mathrm{Tl}^{-/-}$retinas, S-cone opsin mRNA was increased more than twofold (Fig. 7C). Immunohistochemical analysis with confocal microscopy further revealed that S-opsin in wild-type retinas was localized in the OS, whereas in $\mathrm{TlX}^{-/-}$retinas it was distributed throughout the ONL (Fig. 7D).

\section{Regulation of genes required for calcium release by TLX}

Among the genes involved in signal transduction, we chose to further analyze those that regulate intracellular 
calcium levels, which are known for their roles in cell proliferation, differentiation, and apoptosis $(\mathrm{Gu}$ et al. 1994; Orrenius and Nicotera 1994; Spitzer et al. 1994; Takuwa et al. 1995). Cacna1d and Cacng5 are two Ltype, voltage-gated calcium channels whose expression was notably up-regulated in the $T \mathrm{Xx}^{-/-}$retinas as early as E14.5, a time point for the differentiation of early-born neurons (Fig. 8A,B).

Another gene regulating intracellular calcium levels is phospholipase C epsilon (Plce1). Activation of Plce1 generates inositol 1,4,5-triphosphate (IP3) and diacyl glycerol (DAG) by hydrolyzing phosphatidylinositol bisphosphate (PIP2). Increased levels of IP3 cause calcium release from intracellular stores via the IP3 receptors (Schmidt et al. 2001). In $\mathrm{TlX}^{-/-}$retinas, expression of Plce1 was up-regulated over fourfold at E14.5 and twofold at P0 (Fig. 8C). To test whether Plce1 was a TLX downstream target, we linked a 3 -kb upstream genomic sequence of the Plce1 promoter to a luciferase reporter and found that TLX could suppress the activity of this reporter in a dose- and DNA-binding-dependent manner (Fig. 8D). A stretch of conserved sequence within the promoter region was identified that is directly and specifically bound by TLX (Fig. 8E).

Elevated intracellular $\mathrm{Ca}^{2+}$ levels trigger the MAPK pathway, a signaling cascade shown to play important roles in neuronal differentiation, maturation, and cell death (Berridge et al. 2000; Taylor 2002). We examined components of the MAPK pathway by using phosphospecific antibodies. Although the level of ERK activation was not significantly altered, $\mathrm{TlX}^{-/-}$retinas had nearly twofold up-regulation of activated p38 and JNK (Fig. 8F), in agreement with pathway analysis of global gene expression profiling and with previous findings that elevated $\mathrm{Ca}^{2+}$ levels lead to the activation of MAP kinases (Agell et al. 2002).

\section{TLX interacts with corepressor Atn1}

While our studies suggest that TLX acts as a transcriptional repressor, the mechanism by which TLX mediates the repression and the identity of associated corepressors remains unclarified. To map the repression domain, a series of TLX deletion constructs was linked to GAL4DBD. Using standard luciferase assays, we found that the LBD of TLX is sufficient for repression while the DBD is dispensable (Fig. 9A,B). Further deletion analysis demonstrated that a region spanning the last 45 amino acids in the $\mathrm{C}$ terminus of TLX is required for transcriptional repression (Fig. 9B).

NCoR and SMRT are established corepressors for many nuclear receptors (Ordentlich et al. 2001). However, our preliminary studies did not detect interaction between these two corepressors and TLX, suggesting that TLX represses transcription through other yet unknown mechanisms (data not shown). To identify the corepressors for TLX, we performed extensive yeast twohybrid screens using a rat hippocampus library and the LBD of TLX as the bait. Three independent positive clones corresponding to the $\mathrm{C}$ terminus of rat Atn1 were recovered from the screens. These clones were retested in the yeast two-hybrid system and found to specifically bind to the LBD (180-385) but not the $\mathrm{N}$ terminus of TLX or a negative control MEF2C (Fig. 9C,E). The interaction between TLX and mouse Atn 1 was also confirmed in mammalian cells. Consistent with our yeast two-hybrid studies, full-length Atn1 was found to bind to the LBD of TLX in vivo (Fig. 9D,E). To further examine this interaction, we conducted a GST pull-down assay using purified, bacterially expressed GST-TLX (amino acids 281-385) and in vitro translated Atn1 proteins. In these assays, TLX specifically binds to the carboxyl region of Atn1, which is consistent with the clones we recovered from our yeast two-hybrid screens (Fig. 9G,H).

These data suggest that Atn 1 is recruited by TLX to repress transcription. However, whether mouse Atn1 works as a transcriptional repressor has not been demonstrated. We tested this possibility using a standard luciferase reporter assay and found that full-length Atn 1 or a truncated version containing the TLX-interacting region can repress transcription (Fig. 9F). This finding is in agreement with the notion that the Drosophila homolog of Atn 1 acts as a transcriptional corepressor during fly development (Zhang et al. 2002) and is consistent with studies on human Atn1 as a putative transcriptional repressor (Wood et al. 2000).
Figure 8. Regulation of the calcium-releasing pathway by TLX. $(A-C)$ Expression analyses of candidate genes by Q-PCR. Gene expression was normalized to that of Hprt and represented as fold changes against expression in wild-type retinas. $N=9$; $\left(^{\star}\right) P<0.05 ;\left(^{\star \star}\right) P<0.01$; $\left({ }^{\star \star \star}\right) P<0.001$. $(D)$ Regulation of Plce1 promoter activity by TLX. Values were normalized to the transfection efficiency control and to that of the pGL3-basic reporter. (E) Direct binding of TLX to the Plce1 promoter was determined by gel shift assays as described in Figure $6 \mathrm{~F}$. Evolutionally conserved sequences that were used for the gel shift assays are shown on the bottom. Numbers indicate the distance from translation start sites. $(F)$ Enhanced activation of p38 and JNK was monitored using phospho-specific antibodies. Ponceau staining of the blot shows protein input.

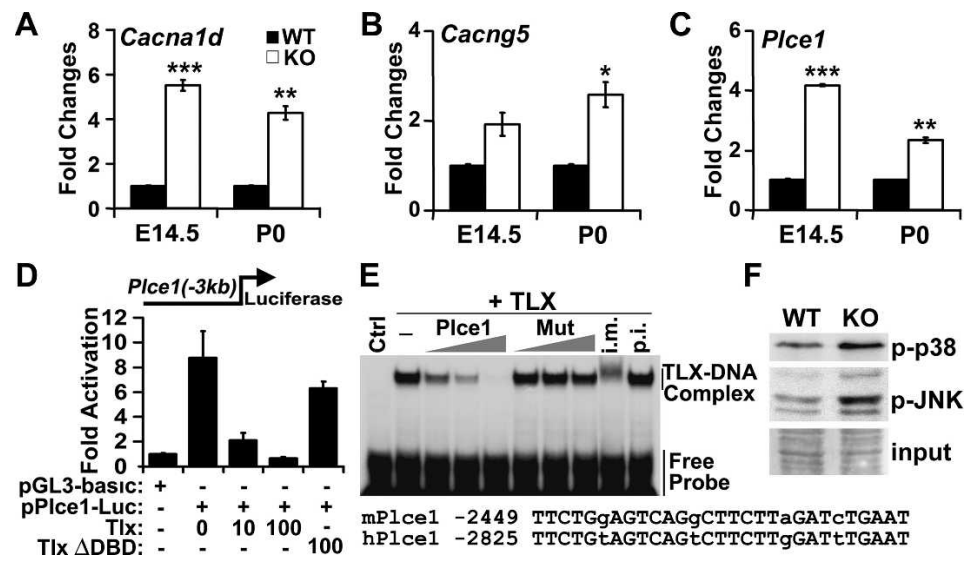




\section{Discussion}

During retinogenesis, RPCs must coordinate two driving forces, proliferation and differentiation. In this study, we show that a single gene, TLX, functions to establish the balance between RPC proliferation and differentiation through three interlinked steps, including (1) the control of proliferation via the Pten-cyclin D1 pathway; (2) the modulation of differentiation through the $\mathrm{PLC}, \mathrm{Ca}^{2+}$ release, and MAPK cascade; and (3) by control of the expression of multiple cell-type-specific regulators, which include bHLH factors, POU domain-containing proteins, and the expression of multiple cytokines and cytokine receptors. Furthermore, we show that the global control by TLX may be mediated through recruitment of the corepressor Atn1, a protein involved in human neurodegenerative disease.

\section{TLX controls the rate of RPC proliferation via Pten-Cyclin D1}

Taking advantage of a $L a c Z$ reporter that is knocked into the Tlx locus, we found that Tlx is highly expressed in

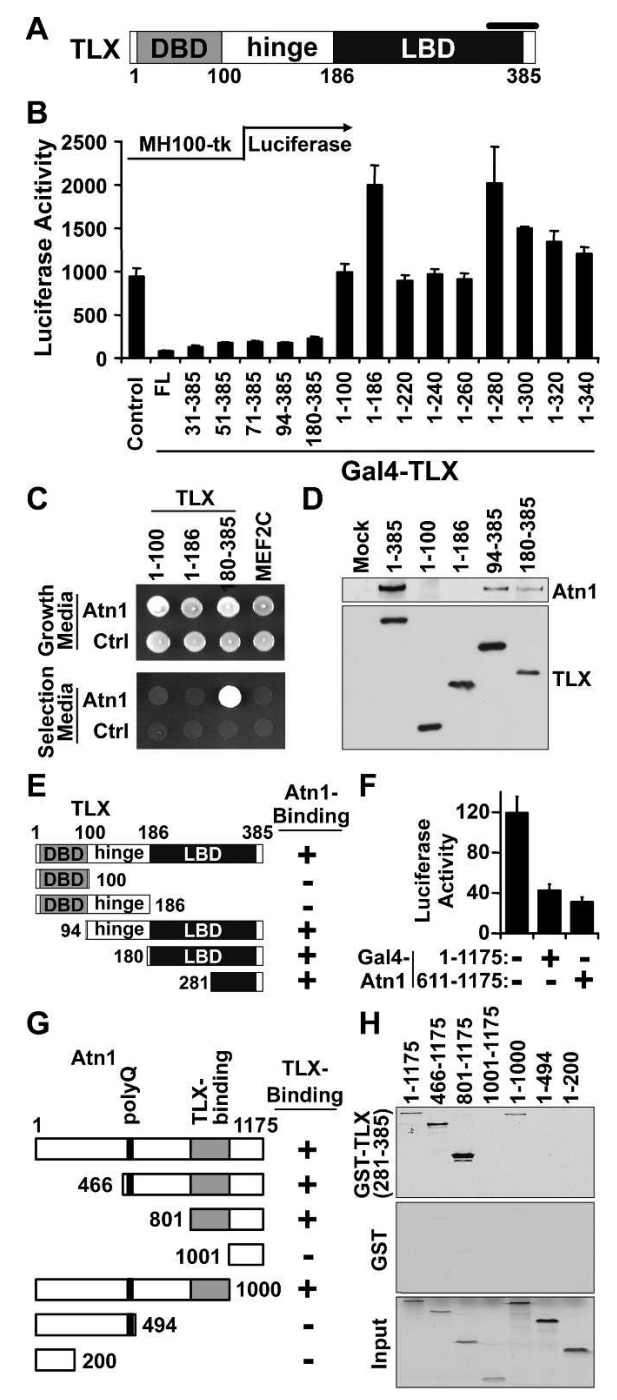

the neuroblastic layer during the early phase of retinogenesis and its expression is down-regulated during neuronal differentiation (Supplementary Fig. S1). Our cell cycle analysis demonstrated that RPCs in the $\mathrm{TlX}^{-/-}$retinas have impaired control of proliferation, which is reflected by their early exit from the cell cycle and the extended cell cycle length. In agreement with our results, others also reported reduced progenitor proliferation in $\mathrm{TlX}^{-/-}$retinas (Miyawaki et al. 2004).

How does loss of TLX function impair RPC proliferation? Previous studies have identified several regulators of RPC proliferation, such as Pax6, Prox1, Rx1, Six3, Six6, Chx10, $p R b$, and p27kip1 (Levine and Green 2004). However, Q-PCR and Western blotting analysis failed to detect any significant changes in the expression of these genes at E14.5, E15.5, E18, P0, P4, P10, or P14, which is consistent with our global gene profiling and suggests that TLX functions downstream or parallel to these genes (Supplementary Fig. S2A,B; data not shown). In regards to the expression of $p 27 k i p 1$, our results differ from a recent report (Miyawaki et al. 2004). This discrepancy might result from uneven immunostaining of the sections and cell counting errors. Expression profiling at E15.5 and P0 revealed that TLX directly binds to the promoter region to inhibit the expression of Pten, a tumor suppressor that negatively regulates the expansion of neural stem cells during mouse cortical development (Groszer et al. 2001).

Overexpression of PTEN alone can induce cell cycle arrest through down-regulation of cyclin D1 via tran-

Figure 9. Interactions between TLX and corepressor atrophin1. (A) Schematic diagram of mouse TLX protein. Full-length protein consists of 385 amino acids and is organized into three major domains: DBD, hinge region, and LBD. The bar over the diagram indicates the minimal region required for repression. (B) Mapping of the minimal region in TLX required for transcriptional repression. Full-length or truncations of TLX were fused to GAL4-DBD and used for reporter assays. (C) Confirmation of the interaction between atrophin1 (Atn1) and TLX in yeast two-hybrid assays. Full-length TLX is toxic to yeast growth, thus it is not included in the test. Yeast transformants were first grown on nonselection media and then equal numbers of cells were spotted on selection or nonselection media for growth tests. MEF2C bait and VP16 prey were used as negative controls (ctrl). ( $D$ ) In vivo interaction between TLX and Atn1 by coimmunoprecipitation assays. HA-tagged Atn1 and Myctagged full-length or truncations of TLX were cotransfected into cells. TLX was immunoprecipitated from cell lysates and the associated Atn1 was detected by Western blotting. Cell lysate transfected with Atn 1 alone (mock) was used as a negative control. (E) Schematic summary of regions in TLX required for binding to Atn1. Results were obtained from yeast two-hybrid $(C)$, coimmunoprecipitation $(D)$, and GST pull-down assays $(H)$. $(F)$ Atn1 represses transcription. Full-length mouse Atn1 or a truncated version was fused to GAL4-DBD and used for transcription reporter assays. $(G)$ Summary of regions in Atn1 required for interaction with TLX. Results were obtained from GST pulldown assays (shown in $H$ ). $(H)$ Physical interactions between TLX and Atn1. Bacterially expressed GST or GST-TLX (281$385)$ and in vitro translated, ${ }^{35}$ S-labeled Atn 1 were used in pulldown assays. 
scriptional and translational mechanisms (Paramio et al. 1999; Weng et al. 2001b; Radu et al. 2003). Expression of cyclin D1 may be additionally regulated by mTOR and p70 S6 kinase signaling pathways, which are significantly altered in $\mathrm{TlX}^{-/-}$retinas (Hashemolhosseini et al. 1998; Gera et al. 2004). Consistent with these observations, our Q-PCR and Western blotting analyses demonstrated that there was a significant decrease in mRNA levels and a dramatic reduction in cyclin D1 protein in $\mathrm{TlX}^{-1-}$ retinas (Fig. 6C; Supplementary Fig. S2C), which was also confirmed by immunohistochemistry (Miyawaki et al. 2004). Decreased expression of cyclin D1 not only results in impaired formation of active complexes with Cdk4 but also retargets the cell cycle inhibitor p27kip1 to cyclin E/Cdk2, which in combination leads to delayed G1/S transition of cell cycle (Hashemolhosseini et al. 1998).

The expression of cyclin D1 and cell cycle progression can also be influenced by other factors that show dysregulation in $\mathrm{TlX}^{-/-}$retinas. Most intriguingly, the expression of DAX1 (NR0B1) is up-regulated at both developmental points in our microarray analysis (Supplementary Table S1). Resembling SHP1 (NR0B2), DAX1 is an orphan nuclear receptor that lacks the conserved DBD. It functions as an inhibitor of nuclear receptor-dependent signaling (for review, see Niakan and McCabe 2005), although we have yet to identify its specific target in the developing retinas (see Supplementary Fig. S3A,B). Catenin beta-interacting protein 1 (Catnbip1), also called ICAT, is another interesting gene that is important for proliferation and is dysregulated in $\mathrm{Tl}^{-/-}$retinas (Supplementary Table S2). Since it represses $\beta$-cateninTcf4-mediated transactivation (Tago et al. 2000), downregulation of $\mathrm{ICAT}$ in $\mathrm{TlX}^{-/-}$retinas may represent a compensatory mechanism.

\section{TLX modulates RPC differentiation through multiple transcription factors}

Retinal cell types are generated sequentially in a defined histogenic order appearing at specified times. This process is severely disrupted in $\mathrm{TlX}^{-/-}$retinas. Compared with wild-type controls at the same developmental stage, $T \mathrm{x}^{-/-}$retinas have more differentiated neurons, fewer proliferating RPCs, and more cells undergoing apoptosis, which in combination lead to progressive retinal dystrophy (Miyawaki et al. 2004; this study). Hence, TLX is essential for maintaining the balance between RPC differentiation and proliferation.

Our gene expression profiling and detailed analyses demonstrate that multiple factors involved in RPC differentiation are modulated by TLX. In $\mathrm{TlX}^{-/-}$retinas, the expression of Poutf and Pnr are dramatically altered. Ngn1, which promotes neuron formation, is another factor up-regulated in the mutant retinas. Additionally, the expression of many other transcription factors potentially involved in RPC differentiation and maturation, such as Foxg1, Foxd1, Pthr1, NrOb1, Tcfap2d, Zic5, Eya2, Ptx3, and Is12, are also notably dysregulated (Supplementary Table S2). However, whether these are direct or indirect targets of TLX and their exact roles in retina formation require further investigation.

\section{Regulation of Plce1-Ca ${ }^{2+}-M A P K$ cascade by TLX}

In this study, we identified Plce1 as a direct downstream target of TLX transcriptional regulation. This is intriguing given the roles that PLC family members play in the regulation of $\mathrm{Ca}^{2+}$ release (Taylor 2002). Plce1 is a new member of the PLC family, and its expression in the CNS correlates well with neuronal differentiation of stem cells (Wu et al. 2003). Furthermore, ectopic expression of Plcel inhibits proliferation of a cancer cell line (Sorli et al. 2005). Cyclic AMP, an inducer for neuronal differentiation, can activate Plcel, which further leads to $\mathrm{Ca}^{2+}$ release and MAPK activation (Schmidt et al. 2001; Agell et al. 2002). We have also demonstrated enhanced activation of p38 and JNK in $\mathrm{TlX}^{-/-}$retinas, which is consistent with the fact that many components of MAP kinase signaling pathways are up-regulated in $\mathrm{TlX}^{-/-}$retinas (Fig. 5C). Together, these results suggest that a Plce1-Ca ${ }^{2+}-$ MAPK cascade may play an unexpected role in TLX-mediated retinodystrophy.

\section{Transcriptional repression by TLX}

Formation of terminal structures during fly embryogenesis requires tailless (t11), the Drosophila homolog of Tlx (Mahoney and Lengyel 1987). TLL functions to establish anterior and posterior subdomains (head and tail regions, respectively) by directly repressing the expression of other gap genes, including kruppel $(\mathrm{kr})$, knirps (kni), and empty spiracles (ems) (Pankratz et al. 1989; Hoch et al. 1992; Hartmann et al. 2001). In mammals, Tlx expression is restricted to the CNS and is required for proper formation of limbic structures (Monaghan et al. 1997). Postnatally, TLX maintains the adult neural stem cells in an undifferentiated state by repressing astrocyte-specific genes, such as GFAP (Shi et al. 2004). Furthermore, our current studies also identified Pten and Plcel as direct downstream target genes repressed by TLX during retinogenesis. Collectively, these data indicate that transcriptional repression mediated by TLX is critical for its function. However, many genes are actually down-regulated in $\mathrm{TlX}^{-/-}$retinas, suggesting that TLX is required in some way for their transcription. Whether these genes are direct targets and whether TLX also activates gene transcription remains unclear at present.

Transcriptional repression by many nuclear receptors are mediated through two well-established corepressors, NCoR and SMRT (Ordentlich et al. 2001). However, we did not detect interaction between either of these corepressors and TLX (data not shown). Rather, our unbiased two-hybrid screens identified Atn1 as a corepressor for TLX. Atn1 is a ubiquitously expressed, evolutionarily conserved gene from flies to humans. The Drosophila homolog (also named grunge) is a transcriptional corepressor for even-skipped and is required for multiple de- 
velopmental processes (Erkner et al. 2002; Zhang et al. 2002). In our current study, we found that mouse Atn 1 is expressed in developing retinas (Supplementary Fig. S3C), and demonstrated that mouse Atn1 represses transcription. Our results showed that binding to Atn 1 is important for TLX-mediated repression, since deletions in the Atn1 interaction region completely abolished the repression by TLX (Fig. 9B, 1-280). Likewise, human Atn1 interacts with ETO/MTG8 and represses transcription; expansion of a polyglutamine repeat (poly-Q) reduces this repressive activity (Wood et al. 2000; Zhang et al. 2002). Most interestingly, poly-Q expansion in Atn1 is responsible for the human neurodegenerative disease, dentatorubral-pallidoluysian atrophy (DRPLA), which is characterized by ataxia, myoclonus, choreoathetosis, epilepsy, and dementia (Koide et al. 1994; Nagafuchi et al. 1994). Considering the important role played by TLX in adult neural stem cell maintenance, it would be interesting to examine whether poly-Q expansion in Atn1 interferes with TLX function and whether DRPLA patients have impaired adult neurogenesis, which may be an underlying contributor to dementia.

In conclusion, our results clearly demonstrate that, by a combination of direct and indirect mechanisms, TLXdependent transcriptional repression serves an essential role in coordinating RPC proliferation and differentiation to prevent retinal malformation and degeneration. It is notable that Tlx is highly expressed in other regions of the CNS, such as forebrain and olfactory bulbs, which are severely affected in $\mathrm{TlX}^{-/-}$mice (Yu et al. 1994; Monaghan et al. 1997; Shi et al. 2004). Interestingly, stem cells in these areas persist in adult animals, raising the possibility that TLX-mediated transcriptional repression may be a critical component in modulating the differentiation and self-renewal of cells in the affected areas.

\section{Materials and methods}

\section{Animals}

The generation and use of TlX-null mice has been described (Yu et al. 2000). Noon of the day of vaginal plugs was designated as E0.5. All mice were housed under a 12-h light/dark cycle and controlled temperature conditions and had free access to food and water. Experimental protocols were approved by the Institutional Animal Care and Use Committee at The Salk Institute for Biological Studies.

\section{Behavior analysis}

Visual acuity was examined using visual cliff and light/dark transition paradigm as described (Crawley 2000). Adult (4- to 5-mo-old) $T l x^{-/-}$mice and littermate wild-type controls $(n \geq 8$ per group) were handled for at least $3 \mathrm{~d}$ before behavioral testing, and they were tested during their active dark cycle.

Immunohistochemistry, in vivo BrdU labeling, and TUNEL assay

After euthanization, eyes from staged embryos and postnatal pups were isolated and fixed with $4 \%$ paraformaldehyde (PFA) in $1 \times \mathrm{PBS}$ at $4^{\circ} \mathrm{C}$ for $2 \mathrm{~h}$. After washing with PBS, tissues were cryoprotected by immersion in $30 \%$ sucrose in PBS, embedded in OCT compound, and sectioned on a cryostat (Leica) at $16 \mu \mathrm{m}$. For immunostaining, sections on slides were rinsed with PBS, permeabilized with PBS containing $0.1 \%$ Triton X-100 (PBST) for $10 \mathrm{~min}$, and blocked for $30 \mathrm{~min}$ with PBST containing $3 \%$ BSA. Sections were incubated with primary antibodies in blocking solution overnight at $4^{\circ} \mathrm{C}$. Alexa 488 - or Alexa 594-conjugated secondary antibodies (Molecular Probes) were used for indirect immunodetection. Proliferating RPCs were labeled with $\mathrm{BrdU}(50 \mathrm{mg} / \mathrm{kg})$ by i.p. injection of pregnant mothers at E15.5 for $1 \mathrm{~h}$. BrdU-labeled cells were detected by using a proliferation detection kit (Roche) and confocal images were obtained (Bio-Rad). For TUNEL assays (Roche), TUNEL-positive cells were counted on five sections per retina, and at least four independent eyes were analyzed for each genotype and normalized to total area measured with the Image (NIH) program. We used the following primary antibodies: anti-rhodopsin (Chemicon, 1:250); anti-cellular retinaldehyde-binding protein $(A B R$, 1:500); anti-recoverin (Chemicon, 1:1000); anti-calbindin (Sigma, 1:2000); anti-calretinin (Novus, 1:200); anti-neuron specific enolase (Chemicon, 1:800); anti-PKC $\alpha$ (Novus, 1:250); antiChx10 (Santa Cruz, 1:100); and anti-S opsin and anti-M opsin (Dr. J. Nathans, Johns Hopkins University School of Medicine, Baltimore, MD, 1:5000). Cone cells were identified with FITCconjugated peanut agglutinin (PNA from Sigma, 1:500). Nuclei were stained with DAPI (Sigma).

Dissociation of retinal cells, cell counting, and FACS analysis

Neural retinas dissected free of surrounding tissues from P0 mice were digested with trypsin $(0.1 \mathrm{mg} / \mathrm{mL})$ in HBSS (Invitrogen) for $10 \mathrm{~min}$ at $37^{\circ} \mathrm{C}$. After gentle trituration with P1000 tips, trypsin inhibitor $(0.1 \mathrm{mg} / \mathrm{mL})$ and DNase I $(20 \mu \mathrm{g} / \mathrm{mL})$ were added and incubated for another $10 \mathrm{~min}$ at $37^{\circ} \mathrm{C}$. Dissociated cells were then fixed with $4 \%$ paraformaldehyde containing DAPI and counted using a cytometer and epifluorescent microscope (Leica). To quantify cell proliferation, dissociated cells were cultured in DMEM:F12 (45:45) medium containing 10\% fetal bovine serum (FBS) for $2 \mathrm{~h}$ at $37^{\circ} \mathrm{C}$ on chamber slides coated with poly-L-Lysine (Becton Dickinson) before addition of $\operatorname{BrdU}(10 \mu \mathrm{M})$ for an additional hour. Proliferating cells and cells in S phase were identified with Ki67 and BrdU labeling, respectively. For FACS analysis of DNA content, dissociated cells were washed with ice-cold PBS and fixed with $70 \%$ ice-cold ethanol for $1 \mathrm{~h}$. Cells were then washed with cold PBS and incubated for $30 \mathrm{~min}$ at $37^{\circ} \mathrm{C}$ in $0.5 \mathrm{~mL}$ PBS containing $10 \mathrm{mg} /$ $\mathrm{mL}$ of propidium iodine (Sigma) and $5 \mathrm{mg} / \mathrm{mL}$ RNase A (Invitrogen). After filtering through a $40-\mu$ m nylon mesh, cells were analyzed on a FACScan (Becton Dickinson). At least four independent experiments were performed for each genotype.

Gene expression profiling and Q-PCR analysis

RNA was isolated from retinas pooled from three staged embryos or neonatal pups. Three pools were collected for each genotype. Preparation of samples, oligonucleotide array hybridization, scanning, and analysis were performed according to Affymetrix protocols. Data with an average fold change of 1.6 at $p \leq 0.05$ for each comparison (total of nine) were considered for GO analysis. VAMPIRE suite (Hsiao et al. 2005) was used for BioCarta pathway annotation. For Q-PCR analysis, $2 \mu \mathrm{g}$ of total RNA from each of three independent pools was used to synthesize first-strand cDNA. PCR primers were designed to span introns whenever possible. Q-PCR reactions were performed in triplicate for each of the pooled samples in 384-well plates. Dis- 
sociation curves were generated to monitor the quality of primer sets, and standard curves were used for quantification.

\section{Protein extraction and immunoblotting}

Retinas from at least three embryos or neonatal pups were lysed directly in SDS sampling buffer, sonicated, and boiled. Equal amounts of proteins were loaded and separated through $8 \%-$ $12 \%$ SDS-PAGE. Western blotting was done as described (Zhang et al. 2001). Anti-PTEN, anti-phospho-PKB-Ser 473, anti-phospho-PDK1 (Cell Signaling Technologies), anti- $\beta$ III-tubulin (Covance), anti-cyclin D1, and anti-cyclin D3 (Upstate) antibodies were used at 1:1000 dilutions.

\section{Transient transfections and gel shift assays}

NIH3T3 and HEK293 cells in 48-well plates were transfected in triplicate with the indicated plasmids using Lipofectamine 2000 (Invitrogen). Transfection efficiency was normalized by cotransfected $\beta$-galactosidase. Cells were harvested $48 \mathrm{~h}$ after transfection, and luciferase and $\beta$-galactosidase activities were measured under conditions of linearity with respect to time and extract concentration. The following plasmids were used: pCMV-LacZ, pGL3-Basic (Promega), pPten (-4 kb)-luciferase, pPlce1 (-3 kb)-luciferase, MH100-tk-luciferase, pCMX-mTlx and deletion constructs as indicated, pM1-mTlx and deletions as indicated, and pM1-mAtn1 and deletions as indicated. Gel shift assays were done as described ( $\mathrm{Yu}$ et al. 1994) using in vitro-translated TLX and ${ }^{32}$ P-labeled double-stranded DNA oligo probes. The probe sequences for Pten promoter are $5^{\prime}$-GG TGCTCAGATAAGTCACTTGGCTGAG-3' and 5'-GCTCAG CCAAGTGACTTATCTGAGCAC-3', and the probe sequences for Plcel promoter are 5'-GTTCTGGAGTCAGGCTTCTTAG ATCTGAAT-3' and 5'-GATTCAGATCTAAGAAGCCTGAC TCCAGAA-3'.

Yeast two-hybrid screen, coimmunoprecipitation, and GST interaction assays

A rat hippocampus cDNA library in HybriZAP vector (Stratagene) was screened with GAL4-TLX (amino acids 180-385) bait in the yeast two-hybrid system, as described previously (Zhang et al. 2001). Positive clones were subjected to specificity tests using the GAL4 DBD alone as bait. Those clones that were specific for interaction with GAL4-TLX bait were sequenced and further analyzed. Coimmunoprecipitation and GST interaction assays were done essentially as described (Zhang et al. 2001). HA-tagged full-length mouse Atn 1 and Myc-tagged fulllength or deletion versions of TLX were used for coimmunoprecipitation assays. GST, GST-TLX (amino acids 281-385), and Flag-tagged, in vitro-translated full-length or deletion versions of Atn1 were used for GST interaction assays.

\section{Acknowledgments}

We thank Dr. J. Nathans for antibodies; Dr. C.A Ross for plasmids; H. Juguilon and Dr. R. Summers for technical support; Dr. N. Tanaka for discussions; Drs. S. Hong, S. Sugii, G. Barish, and $\mathrm{H}$. Cho for critical reading of this manuscript; and E. Stevens and L. Ong for administrative assistance. R.M.E. is an Investigator of the Howard Hughes Medical Institute at the Salk Institute for Biological Studies and March of Dimes Chair in Molecular and Developmental Biology. This work is supported by the National Institute of Aging and NINDS (to F.H.G.), Howard Hughes Medical Institute, NIH HD27183, and Merck \& Co. (to
R.M.E.). C.L.Z is a Howard Hughes Medical Institute Fellow of Life Sciences Research Foundation.

\section{References}

Agell, N., Bachs, O., Rocamora, N., and Villalonga, P. 2002. Modulation of the Ras/Raf/MEK/ERK pathway by $\mathrm{Ca}^{2+}$, and calmodulin. Cell. Signal. 14: 649-654.

Berridge, M.J., Lipp, P., and Bootman, M.D. 2000. The versatility and universality of calcium signalling. Nat. Rev. Mol. Cell Biol. 1: 11-21.

Bramblett, D.E., Pennesi, M.E., Wu, S.M., and Tsai, M.J. 2004. The transcription factor Bhlhb4 is required for rod bipolar cell maturation. Neuron 43: 779-793.

Crawley, J.N. 2000. What's wrong with my mouse? Behavioral phenotyping of transgenic and knockout mice. Wiley-Liss, New York.

DiSalvo, C.V., Zhang, D., and Jacobberger, J.W. 1995. Regulation of NIH-3T3 cell G1 phase transit by serum during exponential growth. Cell Prolif. 28: 511-524.

Downward, J. 2004. PI 3-kinase, Akt and cell survival. Semin. Cell Dev. Biol. 15: 177-182.

Dyer, M.A. 2003. Regulation of proliferation, cell fate specification and differentiation by the homeodomain proteins Prox1, Six3, and Chx10 in the developing retina. Cell Cycle 2: 350-357.

Dyer, M.A. and Cepko, C.L. 2001. p27Kip1 and p57Kip2 regulate proliferation in distinct retinal progenitor cell populations. J. Neurosci. 21: 4259-4271.

Erkner, A., Roure, A., Charroux, B., Delaage, M., Holway, N., Core, N., Vola, C., Angelats, C., Pages, F., Fasano, L., et al. 2002. Grunge, related to human Atrophin-like proteins, has multiple functions in Drosophila development. Development 129: 1119-1129.

Gera, J.F., Mellinghoff, I.K., Shi, Y., Rettig, M.B., Tran, C., Hsu, J.H., Sawyers, C.L., and Lichtenstein, A.K. 2004. AKT activity determines sensitivity to mammalian target of rapamycin (mTOR) inhibitors by regulating cyclin D1 and c-myc expression. J. Biol. Chem. 279: 2737-2746.

Gingras, A.C., Raught, B., and Sonenberg, N. 2001. Regulation of translation initiation by FRAP/mTOR. Genes \& Dev. 15: 807-826.

Gottschalk, A.R., Basila, D., Wong, M., Dean, N.M., Brandts, C.H., Stokoe, D., and Haas-Kogan, D.A. 2001. p27Kip1 is required for PTEN-induced G1 growth arrest. Cancer Res. 61: 2105-2111.

Groszer, M., Erickson, R., Scripture-Adams, D.D., Lesche, R., Trumpp, A., Zack, J.A., Kornblum, H.I., Liu, X., and Wu, H. 2001. Negative regulation of neural stem/progenitor cell proliferation by the Pten tumor suppressor gene in vivo. Science 294: 2186-2189.

$\mathrm{Gu}$, X., Olson, E.C., and Spitzer, N.C. 1994. Spontaneous neuronal calcium spikes and waves during early differentiation. J. Neurosci. 14: 6325-6335.

Haider, N.B., Jacobson, S.G., Cideciyan, A.V., Swiderski, R., Streb, L.M., Searby, C., Beck, G., Hockey, R., Hanna, D.B., Gorman, S., et al. 2000. Mutation of a nuclear receptor gene, NR2E3, causes enhanced S cone syndrome, a disorder of retinal cell fate. Nat. Genet. 24: 127-131.

Hartmann, B., Reichert, H., and Walldorf, U. 2001. Interaction of gap genes in the Drosophila head: tailless regulates expression of empty spiracles in early embryonic patterning and brain development. Mech. Dev. 109: 161-172.

Hashemolhosseini, S., Nagamine, Y., Morley, S.J., Desrivieres, S., Mercep, L., and Ferrari, S. 1998. Rapamycin inhibition of the G1 to $S$ transition is mediated by effects on cyclin D1 
mRNA and protein stability. J. Biol. Chem. 273: 1442414429.

Hatakeyama, J. and Kageyama, R. 2004. Retinal cell fate determination and bHLH factors. Semin. Cell Dev. Biol. 15: 8389.

Hoch, M., Gerwin, N., Taubert, H., and Jackle, H. 1992. Competition for overlapping sites in the regulatory region of the Drosophila gene Kruppel. Science 256: 94-97.

Hsiao, A., Ideker, T., Olefsky, J.M., and Subramaniam, S. 2005. VAMPIRE microarray suite: A Web-based platform for the interpretation of gene expression data. Nucleic Acids Res. 33: W627-W632.

Koide, R., Ikeuchi, T., Onodera, O., Tanaka, H., Igarashi, S., Endo, K., Takahashi, H., Kondo, R., Ishikawa, A., Hayashi, T., et al. 1994. Unstable expansion of CAG repeat in hereditary dentatorubral-pallidoluysian atrophy (DRPLA). Nat. Genet. 6: 9-13.

Levine, E.M. and Green, E.S. 2004. Cell-intrinsic regulators of proliferation in vertebrate retinal progenitors. Semin. Cell Dev. Biol. 15: 63-74.

Li, S., Mo, Z., Yang, X., Price, S.M., Shen, M.M., and Xiang, M. 2004. Foxn 4 controls the genesis of amacrine and horizontal cells by retinal progenitors. Neuron 43: 795-807.

Liu, W., Khare, S.L., Liang, X., Peters, M.A., Liu, X., Cepko, C.L., and Xiang, M. 2000. All Brn3 genes can promote retinal ganglion cell differentiation in the chick. Development 127: 3237-3247.

Liu, W., Mo, Z., and Xiang, M. 2001. The Ath5 proneural genes function upstream of Brn3 POU domain transcription factor genes to promote retinal ganglion cell development. Proc. Natl. Acad. Sci. 98: 1649-1654.

Ma, C., Papermaster, D., and Cepko, C.L. 1998. A unique pattern of photoreceptor degeneration in cyclin D1 mutant mice. Proc. Natl. Acad. Sci. 95: 9938-9943.

Mahoney, P.A. and Lengyel, J.A. 1987. The zygotic segmentation mutant tailless alters the blastoderm fate map of the Drosophila embryo. Dev. Biol. 122: 464-470.

Mangelsdorf, D.J. and Evans, R.M. 1995. The RXR heterodimers and orphan receptors. Cell 83: 841-850.

Marquardt, T. and Gruss, P. 2002. Generating neuronal diversity in the retina: One for nearly all. Trends Neurosci. 25: 32-38.

Martinez-Morales, J.R., Signore, M., Acampora, D., Simeone, A., and Bovolenta, P. 2001. Otx genes are required for tissue specification in the developing eye. Development 128: 20192030.

Mathers, P.H. and Jamrich, M. 2000. Regulation of eye formation by the Rx and pax6 homeobox genes. Cell. Mol. Life Sci. 57: 186-194.

Mears, A.J., Kondo, M., Swain, P.K., Takada, Y., Bush, R.A., Saunders, T.L., Sieving, P.A., and Swaroop, A. 2001. Nrl is required for rod photoreceptor development. Nat. Genet. 29: 447-452.

Miyawaki, T., Uemura, A., Dezawa, M., Yu, R.T., Ide, C., Nishikawa, S., Honda, Y., Tanabe, Y., and Tanabe, T. 2004. Tlx, an orphan nuclear receptor, regulates cell numbers and astrocyte development in the developing retina. J. Neurosci. 24: 8124-8134.

Monaghan, A.P., Bock, D., Gass, P., Schwager, A., Wolfer, D.P., Lipp, H.P., and Schutz, G. 1997. Defective limbic system in mice lacking the tailless gene. Nature 390: 515-517.

Nagafuchi, S., Yanagisawa, H., Ohsaki, E., Shirayama, T., Tadokoro, K., Inoue, T., and Yamada, M. 1994. Structure and expression of the gene responsible for the triplet repeat disorder, dentatorubral and pallidoluysian atrophy (DRPLA). Nat. Genet. 8: 177-182.
Niakan, K.K. and McCabe, E.R. 2005. DAX1 origin, function, and novel role. Mol. Genet. Metab. 86: 70-83.

Ordentlich, P., Downes, M., and Evans, R.M. 2001. Corepressors and nuclear hormone receptor function. Curr. Top. Microbiol. Immunol. 254: 101-116.

Orrenius, S. and Nicotera, P. 1994. The calcium ion and cell death. J. Neural Transm. Suppl. 43: 1-11.

Pankratz, M.J., Hoch, M., Seifert, E., and Jackle, H. 1989. Kruppel requirement for knirps enhancement reflects overlapping gap gene activities in the Drosophila embryo. Nature 341: 337-340.

Paramio, J.M., Navarro, M., Segrelles, C., Gomez-Casero, E., and Jorcano, J.L. 1999. PTEN tumour suppressor is linked to the cell cycle control through the retinoblastoma protein. Oncogene 18: 7462-7468.

Price, J., Turner, D., and Cepko, C. 1987. Lineage analysis in the vertebrate nervous system by retrovirus-mediated gene transfer. Proc. Nat1. Acad. Sci. 84: 156-160.

Radu, A., Neubauer, V., Akagi, T., Hanafusa, H., and Georgescu, M.M. 2003. PTEN induces cell cycle arrest by decreasing the level and nuclear localization of cyclin D1. Mol. Cell. Biol. 23: 6139-6149.

Schmidt, M., Evellin, S., Weernink, P.A., von Dorp, F., Rehmann, H., Lomasney, J.W., and Jakobs, K.H. 2001. A new phospholipase-C-calcium signalling pathway mediated by cyclic AMP and a Rap GTPase. Nat. Cell Biol. 3: 1020-1024.

Scholzen, T. and Gerdes, J. 2000. The Ki-67 protein: From the known and the unknown. J. Cell. Physiol. 182: 311-322.

Shi, Y., Chichung Lie, D., Taupin, P., Nakashima, K., Ray, J., $\mathrm{Yu}$, R.T., Gage, F.H., and Evans, R.M. 2004. Expression and function of orphan nuclear receptor TLX in adult neural stem cells. Nature 427: 78-83.

Sorli, S.C., Bunney, T.D., Sugden, P.H., Paterson, H.F., and Katan, M. 2005. Signaling properties and expression in normal and tumor tissues of two phospholipase C epsilon splice variants. Oncogene 24: 90-100.

Spitzer, N.C., Gu, X., and Olson, E. 1994. Action potentials, calcium transients and the control of differentiation of excitable cells. Curr. Opin. Neurobiol. 4: 70-77.

Tago, K., Nakamura, T., Nishita, M., Hyodo, J., Nagai, S., Murata, Y., Adachi, S., Ohwada, S., Morishita, Y., Shibuya, H., et al. 2000. Inhibition of Wnt signaling by ICAT, a novel $\beta$-catenin-interacting protein. Genes \& Dev. 14: 1741-1749.

Takuwa, N., Zhou, W., and Takuwa, Y. 1995. Calcium, calmodulin and cell cycle progression. Cell. Signal. 7: 93104.

Taylor, C.W. 2002. Controlling calcium entry. Cell 111: $767-$ 769.

Turner, D.L. and Cepko, C.L. 1987. A common progenitor for neurons and glia persists in rat retina late in development. Nature 328: 131-136.

Wang, S.W., Mu, X., Bowers, W.J., Kim, D.S., Plas, D.J., Crair, M.C., Federoff, H.J., Gan, L., and Klein, W.H. 2002. Brn3b/ Brn3c double knockout mice reveal an unsuspected role for Brn3c in retinal ganglion cell axon outgrowth. Development 129: 467-477.

Weng, L., Brown, J., and Eng, C. 2001a. PTEN induces apoptosis and cell cycle arrest through phosphoinositol-3-kinase/Aktdependent and -independent pathways. Hum. Mol. Genet. 10: $237-242$.

. 2001b. PTEN coordinates G(1) arrest by down-regulating cyclin D1 via its protein phosphatase activity and upregulating p27 via its lipid phosphatase activity in a breast cancer model. Hum. Mol. Genet. 10: 599-604.

Wood, J.D., Nucifora Jr., F.C., Duan, K., Zhang, C., Wang, J., Kim, Y., Schilling, G., Sacchi, N., Liu, J.M., and Ross, C.A. 


\section{Zhang et al.}

2000. Atrophin-1, the dentato-rubral and pallido-luysian atrophy gene product, interacts with ETO/MTG8 in the nuclear matrix and represses transcription. J. Cell Biol. 150: 939-948.

Wu, D., Tadano, M., Edamatsu, H., Masago-Toda, M., Yamawaki-Kataoka, Y., Terashima, T., Mizoguchi, A., Minami, Y., Satoh, T., and Kataoka, T. 2003. Neuronal lineage-specific induction of phospholipase Cepsilon expression in the developing mouse brain. Eur. J. Neurosci. 17: 1571-1580.

Yu, R.T., McKeown, M., Evans, R.M., and Umesono, K. 1994. Relationship between Drosophila gap gene tailless and a vertebrate nuclear receptor Tlx. Nature 370: 375-379.

Yu, R.T., Chiang, M.Y., Tanabe, T., Kobayashi, M., Yasuda, K., Evans, R.M., and Umesono, K. 2000. The orphan nuclear receptor Tlx regulates Pax 2 and is essential for vision. Proc. Nat1. Acad. Sci. 97: 2621-2625.

Zhang, C.L., McKinsey, T.A., Lu, J.R., and Olson, E.N. 2001. Association of $\mathrm{COOH}$-terminal-binding protein $(\mathrm{CtBP})$ and MEF2-interacting transcription repressor (MITR) contributes to transcriptional repression of the MEF2 transcription factor. J. Biol. Chem. 276: 35-39.

Zhang, S., Xu, L., Lee, J., and Xu, T. 2002. Drosophila atrophin homolog functions as a transcriptional corepressor in multiple developmental processes. Cell 108: 45-56. 


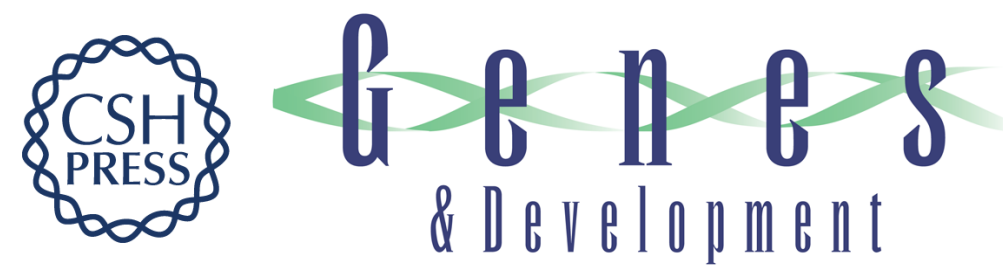

\section{Nuclear receptor TLX prevents retinal dystrophy and recruits the corepressor atrophin1}

Chun-Li Zhang, Yuhua Zou, Ruth T. Yu, et al.

Genes Dev. 2006, 20:

Access the most recent version at doi:10.1101/gad.1413606

Supplemental http://genesdev.cshlp.org/content/suppl/2006/04/27/20.10.1308.DC1
Material

References This article cites 58 articles, 20 of which can be accessed free at:

http://genesdev.cshlp.org/content/20/10/1308.full.html\#ref-list-1

License

Email Alerting

Receive free email alerts when new articles cite this article - sign up in the box at the top

Service

right corner of the article or click here.

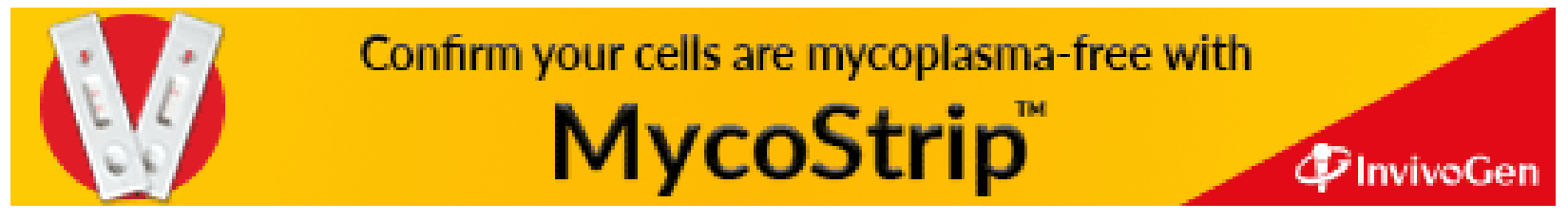

